\title{
Metastatic pancreatic carcinoma to the orbital apex presenting as a superior divisional third cranial nerve palsy
}

This article was published in the following Dove Press journal:

Clinical Ophthalmology

22 November 2012

Number of times this article has been viewed

\author{
Paula E Pecen' \\ Nicholas A Ramey' \\ Michael J Richard' \\ M Tariq Bhatti ${ }^{1,2}$ \\ 'Department of Ophthalmology, \\ Duke University Eye Center, Durham, \\ NC, USA; ${ }^{2}$ Department of Medicine \\ (Division of Neurology), Duke \\ University Medical Center, Durham, \\ NC, USA
}

\begin{abstract}
Metastatic tumors to the orbit are rare, especially from a primary pancreatic carcinoma. A 59-year-old man presented with 4 weeks of right eye pain and eyelid swelling. There was right upper eyelid ptosis associated with a right supraduction deficit consistent with a superior divisional third cranial nerve (CN III) palsy. Magnetic resonance imaging revealed a right orbital apex lesion. A right orbital exenteration was performed for intractable and severe pain. Surgical pathology demonstrated a poorly differentiated carcinoma that was ultimately felt to be derived from the pancreas. In this report, we describe the clinical and neurological imaging findings of a superior divisional CN III palsy as the presenting manifestation of a presumed metastatic pancreatic carcinoma to the orbital apex, and review the neuroanatomy of CN III with particular emphasis on the anatomical bifurcation of the nerve into a superior and inferior division.
\end{abstract}

Keywords: orbital tumor, orbital metastasis, superior division, third cranial nerve palsy

\section{Case report}

A 59-year-old man presented with a four-week history of diplopia, eyelid swelling, ptosis, and proptosis of the right eye. Ocular and neurological examination results were normal, with the exception of $5 \mathrm{~mm}$ of right eye axial proptosis, complete right upper eyelid ptosis, and limitation of supraduction of the right eye (Figure 1A). Visual acuity was 20/30 OD and 20/20 OS. Pupils were equal. Cranial and orbital magnetic resonance imaging (MRI) with contrast and fat suppression revealed a wellcircumscribed enhancing intraconal mass centered around the superior rectus muscle at the right orbital apex (Figure 1B). Biopsy of the mass by anterior orbitotomy revealed fibrous adipose tissue consistent with a benign lipoma. Two months later, a follow-up MRI showed the orbital mass had doubled in size (Figure 1B).

Four months after symptom onset, the patient had visual acuity 20/60 OD and stable $5 \mathrm{~mm}$ proptosis. A discussion regarding surgical debulking was discussed with the patient, but he elected to undergo right orbital exenteration for severe, intractable pain resistant to oral analgesics. Histopathological examination revealed a poorly circumscribed tumor containing poorly differentiated carcinoma, which was concerning for myoepithelial carcinoma or metastasis. Computed tomography of the chest, abdomen, and pelvis revealed a large ill-defined hypodense liver mass and a retroperitoneal mass extending from the pancreatic head with numerous surrounding enlarged lymph nodes - highly suggestive of a primary pancreatic malignancy with metastatic disease. An ultrasound-guided biopsy of the liver mass revealed a poorly differentiated non-small cell carcinoma of unknown primary origin, with characteristics similar to the previously excised right orbital mass. Though the 

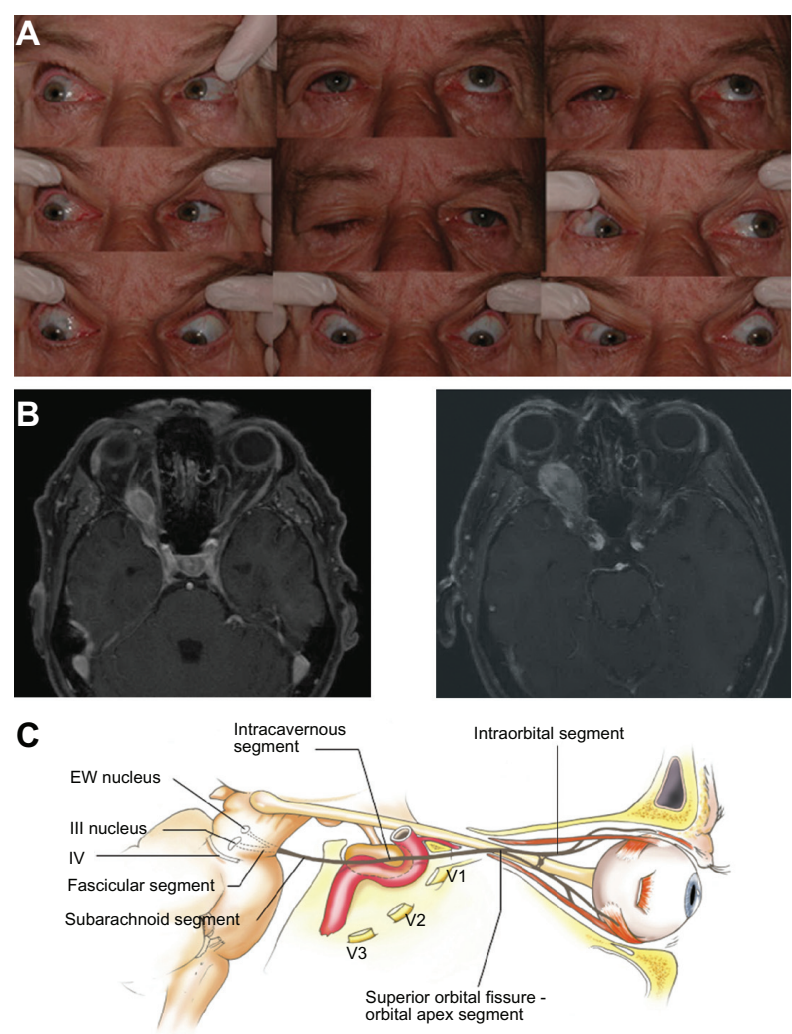

Figure I (A) Ocular motility in the nine cardinal positions of gaze. There is a complete right upper-eyelid ptosis (center panel, center row). In addition, there is limited elevation of the right eye (upper row). The clinical findings are consistent with a right superior divisional CN III palsy. (Patient consent obtained to present clinical images). (B) Axial, contrast-enhanced, TI-weighted magnetic resonance images with fat suppression show a right orbital apex enhancing mass one month after symptom onset (left, measuring $1.6 \mathrm{~cm} \times 1.0 \mathrm{~cm}$ ) and 2 months later (right, measuring $3.1 \mathrm{~cm} \times 1.7 \mathrm{~cm}$ ). (C) Sagittal view of CN III.

Notes: Patient consent obtained to present clinical images. Reprinted from Survey of Ophthalmology, 49, Foroozan R, Bhatti MT, Rhoton AL, Transsphenoidal diplopia, 349-358, copyright (2004), with permission from Elsevier. ${ }^{6}$

Abbreviations: EW, Edinger-Westphal; III, third cranial nerve; IV, fourth cranial nerve; VI, ophthalmic branch of fifth cranial nerve; V2 maxillary branch of fifth cranial nerve; $\mathrm{V} 3$, mandibular branch of fifth cranial nerve.

primary site was never fully elucidated, it was presumed to be a primary pancreatic carcinoma. Palliative chemotherapy was initiated. The patient succumbed to his disease 7 months after initial presentation. No autopsy was performed.

\section{Discussion}

Metastatic disease is the most common cause of intraocular and orbital tumors in adults. ${ }^{1}$ The most frequent site of a primary malignancy to metastasize to the orbit is the breast, followed by the lung. ${ }^{1}$ Orbital metastatic disease carries a very poor prognosis; the median survival of metastatic carcinoma to the orbit is 15.6 months from the time of histopathologic diagnosis. ${ }^{1}$ Orbital metastasis from a pancreatic primary carcinoma is rare, with only four previously reported cases in the English literature. ${ }^{2-5}$ Our case is particularly interesting and clinically relevant because of the unique presentation of a superior divisional third cranial nerve (CN III) palsy as the presenting manifestation of an orbital apex lesion.

The ocular motility deficits associated with orbital tumors can be restrictive, mechanical, or paretic (ocular motor cranial neuropathy) in nature. Our patient presented with limited supraduction and complete ptosis with a relatively small $1.6 \mathrm{~cm} \times 1.0 \mathrm{~cm}$ orbital tumor, which was thought to be due to a superior divisional CN III palsy, as opposed to mechanical compression of the superior rectus and levator palpebrae superioris muscles.

Depending on the anatomical site of the lesion, several patterns of ocular motility dysfunction can be associated with a CN III palsy (Table 1). CN III innervates the levator palpebrae superioris, pupillary sphincter, and four of the six extraocular muscles. The nerve exits the midbrain ventrally as a single trunk, enters the subarachnoid space from the interpeduncular fossa, travels along the lateral wall of the cavernous sinus, and then enters the orbit through the superior orbital fissure (Figure 1C). Either within the cavernous sinus or the superior orbital fissure, the nerve divides into two branches, a smaller superior ramus and a larger inferior ramus. After entering the orbit, the superior division of CN III travels superomedially over the optic nerve to supply the superior rectus and levator palpebrae superioris muscles.

Clinically, a superior divisional CN III palsy is characterized by upper-eyelid ptosis and limited supraduction (in particular, when the eye is in an abducted position). Although the anatomical division of CN III occurs in the region of the anterior cavernous sinus-superior orbital fissure, the axons of the nerve are topographically arranged within the brainstem and subarachnoid space. This anatomical arrangement explains why a lesion of the fascicular or subarachnoid portions of CN III (prior to the anatomical bifurcation) can result in a divisional (superior or inferior) palsy. In addition, a lesion in the superior orbital apex (as in our patient) can preferentially affect the superior division of CN III. Our review of the literature revealed no previous report of a superior divisional CN III palsy due to an orbital tumor.

Although rare, clinicians should be aware that a divisional $\mathrm{CN}$ III palsy can be indicative of not only an intracranial lesion, but also an intraorbital lesion. Appropriate radiologic studies of the brain and orbit should be performed. If an intraorbital lesion is identified, a histopathologic diagnosis should be immediately pursued to confirm the diagnosis. Given the grave prognosis for metastatic orbital tumors, early diagnosis and treatment is paramount and may potentially improve the survival rate. ${ }^{5}$ 
Table I Anatomical site of lesion, resulting in ocular motility dysfunction, and associated clinical findings of third cranial nerve palsies

\begin{tabular}{|c|c|c|}
\hline Anatomical site & Ocular motility dysfunction & Associated clinical findings \\
\hline \multirow[t]{6}{*}{ Midbrain - nuclear } & \pm bilateral pupil involvement & Supranuclear ocular \\
\hline & \pm bilateral ptosis & Motility deficits \\
\hline & Incomplete paresis & Supranuclear gaze palsies \\
\hline & Isolated extraocular muscle & Ataxia \\
\hline & Contralateral superior rectus & Hemihypesthesia \\
\hline & Muscle paresis & \\
\hline \multirow[t]{7}{*}{ Midbrain - fascicular } & Complete or incomplete & Ipsilateral cerebellar ataxia \\
\hline & Divisional paresis & Nothnagel's syndrome \\
\hline & \pm pupil involvement & Contralateral intention \\
\hline & & Tremor \\
\hline & & (Benedikt's syndrome) \\
\hline & & Contralateral hemiparesis \\
\hline & & Weber's syndrome \\
\hline \multirow[t]{6}{*}{ Subarachnoid space } & Complete or incomplete & Multiple ocular motor \\
\hline & Divisional paresis & Cranial neuropathies \\
\hline & \pm pupil involvement & Meningeal irritation \\
\hline & & Mental status changes \\
\hline & & Increased intracranial \\
\hline & & Pressure \\
\hline Cavernous sinus/superior orbital & Complete or incomplete & Multiple ocular motor \\
\hline \multirow[t]{3}{*}{ fissure/intraorbital } & Divisional paresis & Cranial neuropathies \\
\hline & \pm pupil involvement & Visual loss \\
\hline & & Proptosis \\
\hline
\end{tabular}

\section{Acknowledgments}

We thank the patient and his family for contributing to this report. This report was supported by a 2011-2012 Duke University unrestricted departmental grant from Research to Prevent Blindness. NAR, MJR, and MTB contributed substantially to the collection of patient information, consent, and treatment. PEP and MTB contributed substantially to drafting the article and revising it critically for important intellectual content. All authors contributed to the final approval of the version to be published.

\section{Disclosure}

The authors report no conflicts of interest in this work.

\section{References}

1. Freedman MI, Folk JC. Metastatic tumors to the eye and orbit. Patient survival and clinical characteristics. Arch Ophthalmol. 1987;105(9):1215-1219.

2. Font RL, Ferry AP. Carcinoma metastatic to the eye and orbit III. A clinicopathlogic study of 28 cases metastatic to the orbit. Cancer. 1976;38(3):1326-1335.

3. Geetha N, Chandralekha B, Kumar A, et al. Carcinoma of the pancreas presenting as an orbital tumor: a case report. Am J Clin Oncol. 1998;21(5):532-533.

4. Foo FY, Lee M, Looi A. Asymptomatic pancreatic adenocarcinoma presenting as an orbital metastatic tumor. Orbit. 2010;29(5): 262-265.

5. Goldberg RA, Rootman J. Clinical characteristics of metastatic orbital tumors. Ophthalmology. 1990;97(5):620-624.

6. Foroozan R, Bhatti MT, Rhoton AL. Transsphenoidal diplopia. Surv Ophthalmol. 2004;49(3):349-358.
Clinical Ophthalmology

\section{Publish your work in this journal}

Clinical Ophthalmology is an international, peer-reviewed journal covering all subspecialties within ophthalmology. Key topics include: Optometry; Visual science; Pharmacology and drug therapy in eye diseases; Basic Sciences; Primary and Secondary eye care; Patient Safety and Quality of Care Improvements. This journal is indexed on

Submit your manuscript here: http://www.dovepress.com/clinical-ophthalmology-journal

\section{Dovepress}

PubMed Central and CAS, and is the official journal of The Society of Clinical Ophthalmology (SCO). The manuscript management system is completely online and includes a very quick and fair peer-review system, which is all easy to use. Visit http://www.dovepress.com/ testimonials.php to read real quotes from published authors. 